UC-46

Reporting Date: June 1975 Issued: November 1975

\title{
Technical Specifications for the Pajarito Site Critical Experiments Facility
}

by

H. C. Paxton 
Printed in the United States of America. Avoilable trom National Technical Information Service

US Depertimint of Commerce

5285 Port hoyal Road

Springfisld, VA 22151

Price: Prinied Copy M.00 Mierolichs $\$ 2.25$

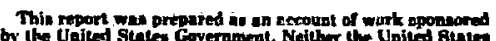

by the United States Goverameal. Neilher (he United Bunted

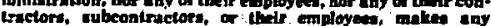

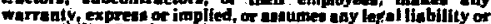

remponabifity for the acouracy, completenea, of to zefulinest of

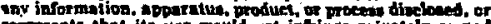

rephisis. 


\section{CONTENTS}

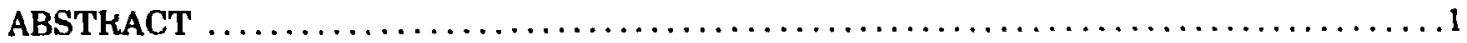

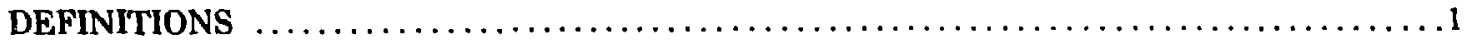

SAFETY LIMIT AND OPERATING LIMIT $\ldots \ldots \ldots \ldots \ldots \ldots \ldots \ldots \ldots \ldots \ldots \ldots \ldots \ldots \ldots \ldots$

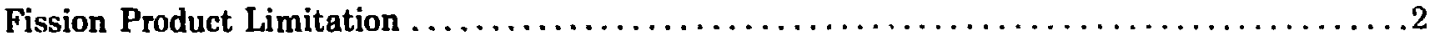

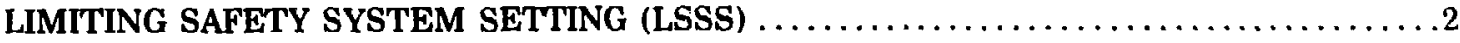

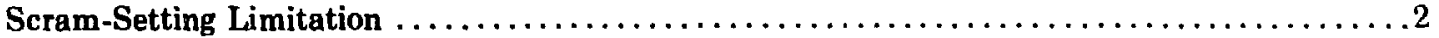

LIMITING CONDITIONS FOR OPERATION (LCO) $\ldots \ldots \ldots \ldots \ldots \ldots \ldots \ldots \ldots \ldots \ldots \ldots \ldots$

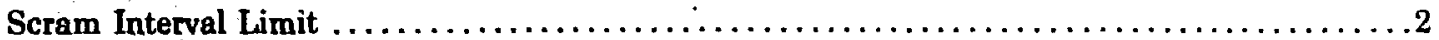

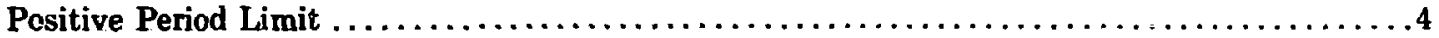

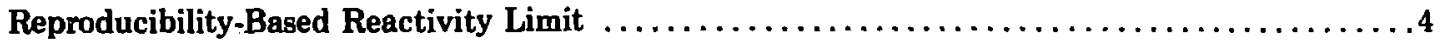

Reactivity Restrictions for Fast Neutron Bursts $\ldots \ldots \ldots \ldots \ldots \ldots \ldots \ldots \ldots \ldots \ldots \ldots \ldots \ldots \ldots$

Reactivity Restrictions for Kinglet Operation $\ldots \ldots \ldots \ldots \ldots \ldots \ldots \ldots \ldots \ldots \ldots \ldots \ldots \ldots \ldots$

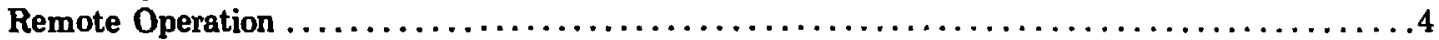

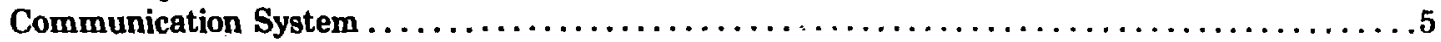

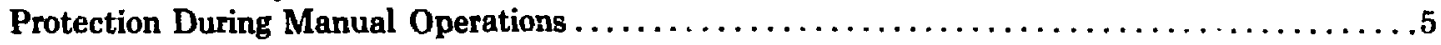

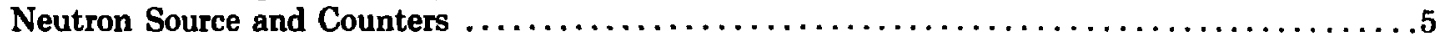

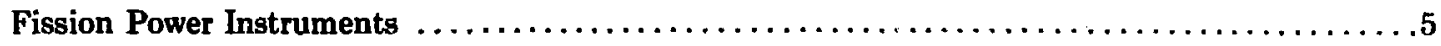

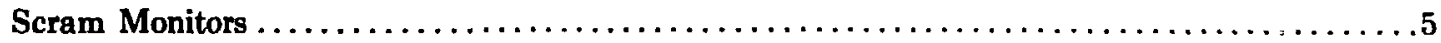

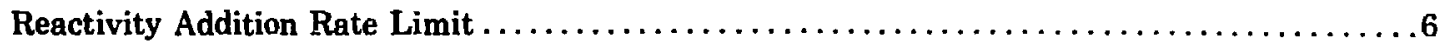

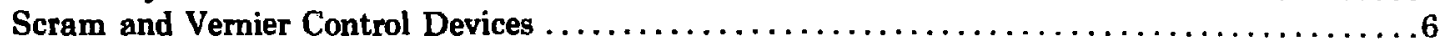

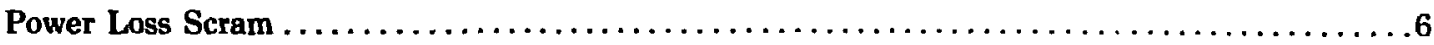

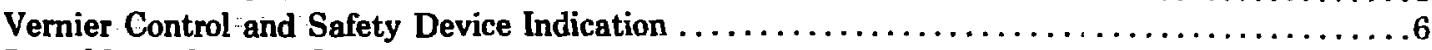

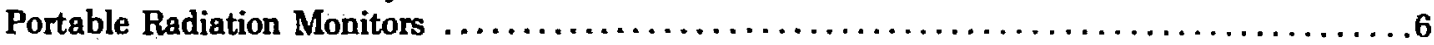

SURVEILLANCE REQUIREMENTS $\ldots \ldots \ldots \ldots \ldots \ldots \ldots \ldots \ldots \ldots \ldots \ldots \ldots \ldots \ldots \ldots \ldots \ldots$

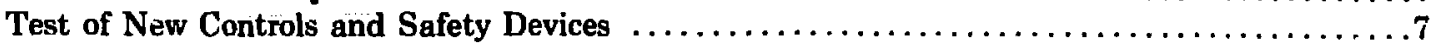

Check of Scram System and Radiation Detectors $\ldots \ldots \ldots \ldots \ldots \ldots \ldots \ldots \ldots \ldots \ldots \ldots \ldots$

Scram Interval Measurement $\ldots \ldots \ldots \ldots \ldots \ldots \ldots \ldots \ldots \ldots \ldots \ldots \ldots \ldots \ldots \ldots \ldots \ldots \ldots \ldots$

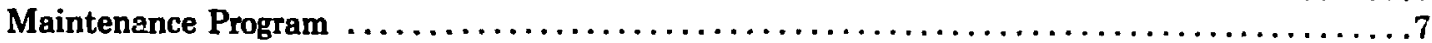

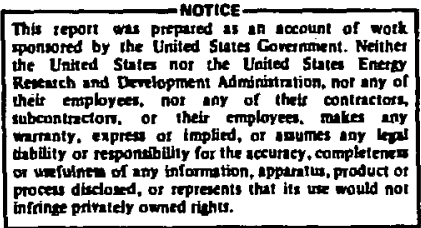


ADMINISTRATIVE CONTROLS

Organization

Action if Technical Specification is Violated

Written Procedures and Approvals

Records

Audits.

Procedural Matters

REFERENCES

Approved:

It It Helmick

For A-5 Safety Committee

$\frac{\text { Stolon F. Hansen }}{\text { Group } A-5}$

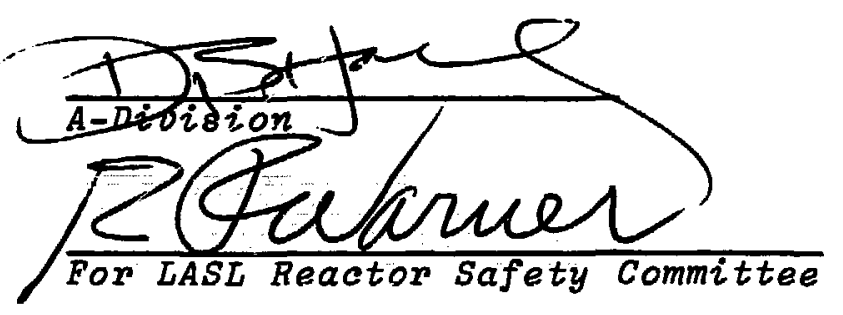

iv 


\title{
TECHNICAL SPECIFICATIONS FOR THE PAJARITO SITE CRITICAL EXPERIMENTS FACILITY \\ by
}

H. C. Paxton

\begin{abstract}
This document is to satisfy the requirement for technical specifications spelled out in ERDA Manual Chapter 0540, "Safety of ERDA-Owned Reactors." Technical specifications are defined in Sec. 0540-048, and the requirement for them appears in Sec. 0540015. The following technical specifications replace the document, "Operating Limits for the Los Alamos Critical Assembly Facility," revised May 27, 1971.
\end{abstract}

\section{DEFINITIONS}

Pajarito Site Critical Experiments Facility: This facility of the Los Alamos Scientific Laboratory is described in "Safety Analysis for the Los Alamos Critical-Assembly Facility," dated November 7 . 1969. ${ }^{1}$

Kiva: As pointed out in Ret. 1, this name is applied to each of the three remote laboratory buildings in which critical experiments are performed.

Critical experiment (experiment): An experiment performed with fissile material at or near criticality.

Critical assembly (assembly): The system containing fissile material with which critical experiments are performed.

Safety device: A mechanism designed to reduce the reactivity of a critical assembly.

Scram: A rapid reduction of reactivity to subcriticality, by means of safety devices.

Scram setting: The minimum radiation monitor signal that automatically trigger: a scram.
Positive period: The time interval during which th power of a supercritical assembly increases by th factor $e$.

Dollar of reactivity: The reactivity incremen hetween delayed and prompt criticality.

Reproducibility-ibased reactivity limit: An uppe limit of reactivity that depends upon th reproducibility demonstrated by a series of dis ussembly and reassembly operations.

Reproducibility (of reactivity): The standar deviation of at least six measurements of the reac tivity at a given assembly configuration.

Damage threshold: The excess reactivity at which prompt critical burst produces a small crack in component, but does not lead to complete rupture

Neutron multiplication: For a subcritice assembly, a neutron counting rate that is sensitive $t$ reactivity change, normalized to a reference cour ting rate (ideally that which would exist if there wer no tissions).

Vernier control (control device): A critic: assembly component intended for fine adjustment 
reactivity. Its function may be incorporated in the assembly and disassembly device used for final approach to criticality.

\section{SAFETY LIMIT AND OPERATING LIMIT}

\section{Fission Product Limitation}

Applicability. The fission procluct limitation applies to all Pajarito systems: Big Ten. Flattop, Godiva IV, Godiva IVA, Honeycomb, Jezebel. Kinglet. Parka, the Plasma Cavity Assembly (Mars machine), and temporary assemblies on Comet. Venus, and Supercomet machines.

Objective. The purpose is to maintain the distinguishing feature of a critical facility, that the fission product inventory of each assembly be limited so that there is no need for special containment. or for auxiliary cooling to prevent damage as a result of afterheating.

\section{Specification.}

Safety Limit. This limit corresponds to a Kiva operation that generates a total of $10^{19}$ fissions within $1 \mathrm{~h}$. A universal means of measurement is radiochemical analysis of a sample of fissile material from the assembly involved.

Operating Limit. Operation shall be controlled so that the fission product power generation in any assembly, when averaged over the first hour after shutdown, does riot exceed $600 \mathrm{~W}$. Figure 1 gives the information required to translate any fission product history into fission product power at any later time. Note that the $600-\mathrm{W}$ limit is the first-hour average that would be generated by a burst of $10^{18}$ fissions.

Bases. The effectiveness of the Pajarito facility protective features is demonstrated by extrapolation of dose rates measured immediately outside control rooms (in line of sight to the Kiva) during normal critical operations. Extrapolated yields that would give the LASL "administrative" whole-body dose limit ( $3 \mathrm{rem}$ ) range from $10^{19}$ to $2 \times 10^{20}$ fissions, depending on the type of assembly and the degree of shielding by Kiva walls. ${ }^{1,2}$ Another iactor of 8 would be required to produce the emergency whole-body dose linit prescribed by 10 CFR Part $100 .{ }^{3}$

Effects of fission product release from any assembly may be related directly to the formalistic treatment in the "Kinglet Safety Analysis." There. the release of al! fission products from a 10 -s run of $1.3 \times 10^{18}$ fissions (corresponding to the operating limit) under the most adverse conditions is shown to produce doses of -less than 5 rad to the whole body or 20 rad to the thyroid at $300 \mathrm{~m}$. It is stated that ronlistic estimates wouid be about two orders of magnitude less, or approximately 0.05 and $0.2 \mathrm{rad}$. respectively.

\section{LIMITING SAFETY SYSTEM SETTING (LSSS)}

\section{Scram-Setting Limitation}

Applicability. The scram setting limitation applies to at least two radiation monitors in use during a critical experiment with any Pajarito assembly:

Objective. The purpose is to implement the above fission product limitation.

Specification. Scram settings at each of two radiation monitors shall not exceed $1 \mathrm{rem} / \mathrm{s}$ for an operation in Kiva 1 or 2 , and $3 \mathrm{rem} / \mathrm{s}$ for an operation in Kiva 3.

Bases. Relative measurements in Kivas and outside control rooms shriw that operation giving the ahove rates would lead to no more than 0.3 -rem dose in $1 \mathrm{~h}$ to a person outdoors. This is the upper dose limit that could be produced by attaining the fission product operating limi' in $1 \mathrm{~h}$.

\section{LIMITING CONDITIONS FOR OPERATION (LCO)}

\section{Scram Interval Limit}

Applicability. The scram interval limit applies to all Pajarito assemblies.

Objective. The purpose is to supplement the above scram LSSS so that the fission product sufety limit will not be exceeded during any accidentally short positive period.

Specification. With all scrams acting, the time from a scram signal to decrease of fission power shall not exceed $0.5 \mathrm{~s}$. 


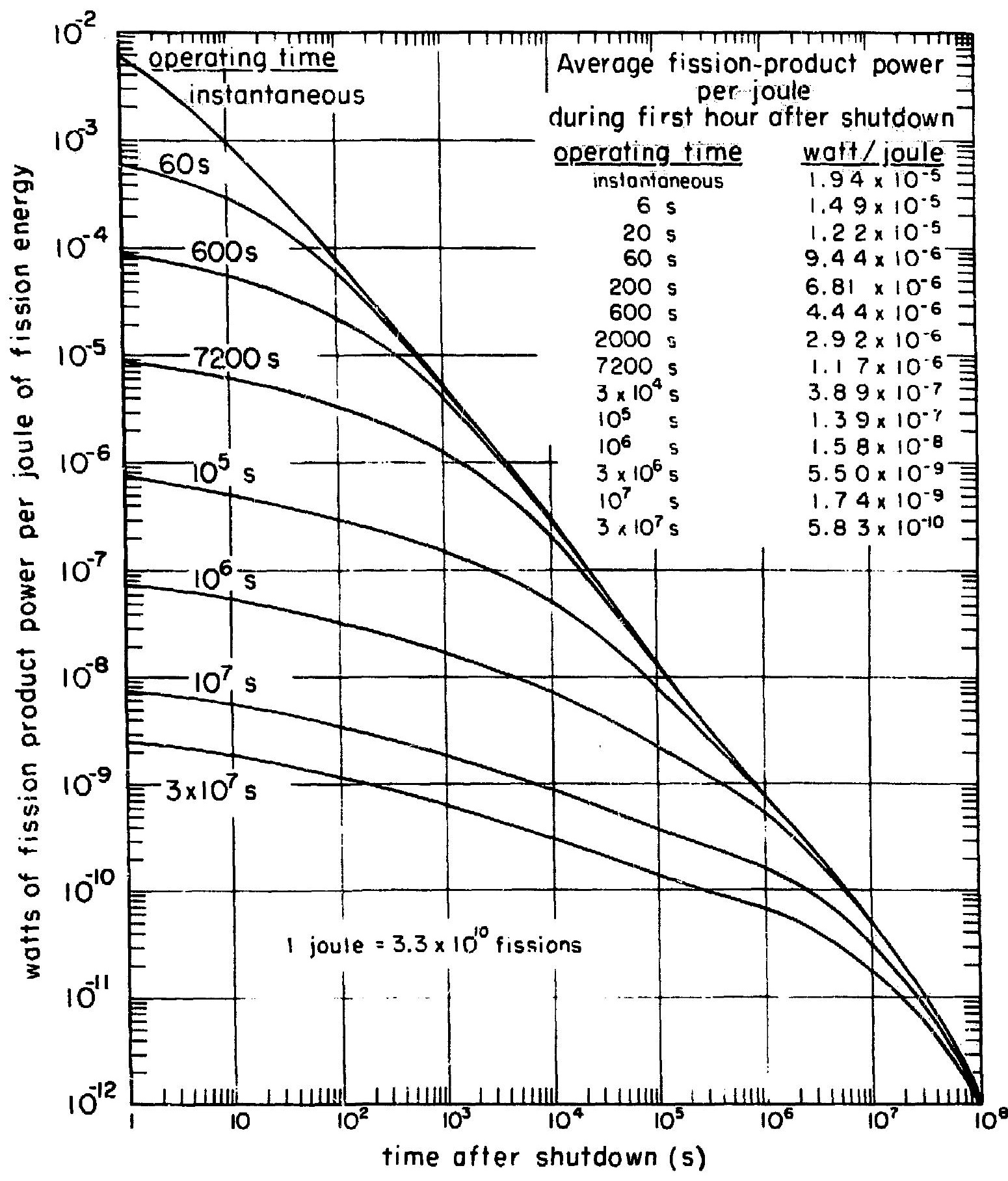

Fig. 1.

Fission product power. 
Basis. At an exceptionally short positive period of (1.5 $\leqslant$, the 0.5-s L.C.O allows only one uncontrolled efolding of power beyond the scram setting, so it prevents escalation to the fission-product safety limil as a result of scram delay.

\section{Positive Period Limit}

Applicability. The positive period limit applies to Comet. Honevcomb, Parka, Plasma Cavity (Mars). Supercomet. and Venus assemblies.

Objective. The purpose is to provide a generous salety margin below prompt criticality, in particular. Io avoid an uncontrolled excursion from assemblies that lack a clearly demonstrated prompt shut down mechanism.

Specification. The excess reactivity. including effects of add-on experiments, shall be limited so that no positive period will be less than $5 \mathrm{~s}$.

Basis. The 5-s minimum positive period provides a margin of more than 0.35 below prompt criticality and is adequate for operator response ${ }^{5}$ to prevent escalation to the fisision proluct safety limit.

\section{Reproducibility-Based Reactivity Limit}

Applicability. 'This limit applies to .Jezebel. Flattop. and Big Ten, and to Godiva IV and IV A during a new appruach to prompt criticality. provided repruducibility has heen established experimentally.

Objective. The purpose is to provide an adequate hut not excessive margin below prompt criticality, in short-period experiments with an assembly for which the effectiveness of a prompt shutdown mechanism is clear.

Specification. The excess reactivity, including effects of add-on experiments, shall be limited to maintain a margin below prompt criticality which is at least three times the reproducibility demonstrated by a series of disassemblies and reassemblies.

Bases. With a margin of three times the experimental reproducibility, prompt criticality is unlikety to be reached; the still greater margin below the damage threshold protects against exceeding the fission product safety limit.

\section{Reactivity Restrictions for Fast Neutron Bursts}

Applicability. These restrictions apply to Godiva IV and IVA.

Objective. The purpose is to prevent a severely damaging excursion.

Specification. The semonstrated reproducibility (adjusted to constant temperature) shall be within \pm 0.002 , and any reactivity increase beyond a value previously attained shall not exceed 0.015 or pass an observable damage threshold.

Bases. According to computations of kinetic energy as a function of excess reactivity. ${ }^{6}$ a step increase of 0.025 heyond the damage threshold would produce less than $0.1 \mathrm{om}$. HE equivalent explosive energy. and the above L.CO guards against half that increase.

\section{Reactivity Restrictions for Kinglet Operation}

Applicability. These restrictions apply to Kinglet.

Objective. The purpose is to prevent rupture if the solution comtainer.

Specification. The demonst rated reproducibility (adjusted to constant temperature) shall be within $\pm(1.02 \%$. and any reactivity inerease beyond a salue previously attained shall not exceed 0.1 is or pass 5.05 superprompt critical.

Bases. KFWB dunamir experiments ${ }^{\top}$ attained excess reactivities more than 6 shove prompt criticality without damage. and the above I.CO is more conservative. Fven escape of Kinplet solution under this condition would not constitute an unac(e)tahle public hazard. ${ }^{+}$Note that the renctivity sicale in dollars is calibrated with stationary fuet.

\section{Remote Operation}

Applicability. The requirement for remote operatim applies to eritical experiments with any Pajarito assembly (p. 2). 
Objective. The purpose is to protect people from radiation resulting from normal operation or an accidental excursion.

Specification. Critical operations, and subcritical operations beyond the provisions of ANSI Standard N16.3-1974. ${ }^{8}$ shall be performed in a Kiva with the exclusion area cleared and secured.

Bases. This is required by "Operating Procedures for the Pajarito Site Criticai Assembly Facility" (Procedures), ${ }^{9}$ and it implements parts of items $\mathbf{3 . 6}$ and 3.7 of ANSI Standard N405-1975. ${ }^{10}$

\section{Communication System}

Applicability. 'This system must be active whenever people may be in a Kiva to prepare for a critical experiment.

Objective. The purpose is to maintain coordination of activities in the control room and the Kiva.

Specification. There shall be a system for communication between personnel at the control console and those in the Kiva.

Basis. This is required by ANSI N405 item 4.2. ${ }^{10}$

\section{Protection During Manual Operations}

Applicability. This requirement applies to any manual operation that is beyond the scope of ANSI Standard N16.1-1975, "l such as building up the active parts of an assembly.

Objective. The purpose is to indicate effects of reactivity changes for the protection of those present during addition of reactivity to an assembly.

Specification. All provisions of ANSI N16.3$1974^{8}$ shall be satisfied during manual reactivity additions.

Bases. This is required by Procedures, ${ }^{9}$ and it implements ANSI N405 item 4.3 and parts of items 3.5 and $4.4 .^{10}$

\section{Neutron Source and Counters}

Applicability. This requirement applies, during any new approach to criticality with any Pajarito assembly (p. 2).

Objective. The purpose is to provide an orderly approach to criticality.

Specification. Neutron counters and a source of neutrons sufficient to produce a valid indication of multiplication shall be present during any approach to criticality, except that the neutron source may be nmitted for special experiments in which reactivity effects have been measured. Each neutron count indicative of multiplication shall have a standard deviation no greater than $\pm 5 \%$.

Bases. This is required by Procedures ${ }^{9}$ and by ANSI N405 item 4.4. ${ }^{10}$

\section{Fission Power Instruments}

Applicability. This requirement applies to any critical experiment with any Pajarito assembly ( $p$. $2)$.

Objective. The purpose is to provide indication of fission power.

Specification. During critical experiments, at least two instruinents shall indicate the neutron level within the assembly: these may be scram monitors.

Basis. This implements ANSI N405 item 4.9. ${ }^{10}$

\section{Seram Monitors}

Applicability. This requirement applies to any critical experiment with any Pajarito assembly ( $p$. 2).

Objective. The purpose is to provide scram signals if fission power exceeds a preset value.

Specification. At least two radial'n monitors shall each be capable of initiating a scram at a preset radiation level. 
Bases. This is required by Procedures ${ }^{9}$ and by ANSI N405 item 4.6. ${ }^{10}$

\section{Reactivity Addition Rate Limit}

Applicability. The reactivity addition rate limit applies to Comet, Honeycomb, Parka, Plasma Cavity (Mars), Supercomet, and Venus assemblies. It also applies to Godiva IV. Godiva IVA, and Kinglet during initial approaches to criticality.

Objective. The purpose is to provide adequate time for operator response in case of a loading error.

Specification. The final rate of assembly of major parts shall be limited so that reactivity cannot be added faster than $0.05 \$ / \mathrm{s}$ when the neutron multiplication is greater than 100 .

Bases. This LCO is required by Procedures. ${ }^{9}$ It does not apply to components that can add no reactivity greater than $0.5 \$$.

\section{Scram and Vernier Control Devices}

Applicability. These requirements apply to all Pajarito assemblies (p. 2).

Objective. The purpose is to provide for orderly approaches to criticality while preventing unplanned excursions.

Specification. Any assembly intended for critical operation shall have at least two independent safety devices that can be scrammed automatically or manually, and a vernier control. The safety devices shall be capable of removing reactivity faster than it can be added. Shutdown shall be at least $5 \$$ total and greater than 18 with any single safety device inoperative.

Any subcritical assembly shall have at least one safety device capable of at least $5 \$$ shutdown.

Bases. This augments ANSI N405 item 4.5, ${ }^{10}$ and is required by Procedures. ${ }^{9}$ Note that an assembly that does not satisfy the requirement for critical operation must be kept subcritical by a margin specified in the experimental plan.9

\section{Power Loss Scram}

Applicability. This requirement applies to all Pajarito assemblies (p. 2).

Objective. The purpose is to establish a safe condition upon loss of actuating power.

Specification. Loss of actuating power or energy supply to the safety system shall produce a scram.

Bases. This is required by Procedures ${ }^{9}$ and by ANSI N405 item 4.7. ${ }^{10}$

\section{Vernier Control and Safety Device Indication}

Applicability. This requirement applies to all Pajarito assemblies (p. 2).

Objective. The purpose is to provide a convenient reactivity index.

Specification. The status of any vernier reactivity control shall be displayed continuously at the con. trol console; "in" and "out" conditions of safety devices shall also be displayed.

Basis. This is required by ANSI N405 item 4.10. ${ }^{10}$

\section{Portable Radiation Monitors}

Applicability. This requirement applies to all critical experiments.

Objective. The purpose is to minimize normal and accidental exposure to radiation from critical assemblies and to guide rescue operations if required because of an accident.

Specification. A porfable gamma meter (0-500 $R / h)$ and a portable alpha meter shall be in each Kiva. and at least one each of these and one highrange gamma meter (0-10 000 $\mathrm{R} / \mathrm{h})$ shall be near the control rooms.

Basis. This implements ANSI N405 item 3.11. ${ }^{10}$ 


\section{SURVEILLANCE REQUIREMENTS}

\section{Test of New Controls and Safety Devices}

Applicability. This requirement applies to all newly installed or significantly altered control equipment and safety devices.

Objective. 'The purpose is to reduce the chance of mallunction during critical experiments.

Specification. The satisfactory performance of new or altezed cont rol and safety equipment shall be established, and adherence to the reactivity addition rate limit shall be confirmed before initial critical operation.

Basis. We consider this requirement of ANSI N4115 item $5.1^{10}$ to be good practice.

\section{Check of Scram System and Radiation Detectors}

Applicability. This requirement applies to each dav's operation of any critical assembly (p. 2).

Objective. The purpose is to verify the operability of scram systems and of instrumentation as preliminaries to each critical experiment.

Specification. The proper functioning of the safety system shall be checked before each day's operation: operability of any vernier control, and the response of scram monitors and radiation detectors to a change of radiation level shall be noted early in each day's operation.

Basis. This is to confirm effectiveness of the safety system: it is called for by Procedures ${ }^{9}$ and by ANSI N405 item 5.2. ${ }^{10}$

\section{Scram Interval Measurement}

Applicability. This requirement applies to each active assembly.

Objective. The $r$ iose is to determine whether the scram interval limitation is satisfied, and to make corrections if necessary.
Specification. The interval from scram signal to decrease of fission power in each active assembly shall he measured at least annually.

Basis. This requirement is related to the effectiveness of excess reactivity (positive period) limitations.

\section{Maintenance Program}

Applicability. This requirement applies to each active assembly machine.

Objective. The purpose is to maintain good uperating conditions.

Specification. Actuating features related to criticality shall be inspected and maintained as required. at least quarterly.

Basis. These routine inspections follow check lists for the individual machines and supplement customary visual checks before each operation.

\section{ADMINISTRATIVE CONTROLS}

\section{Organization}

The administrative chain extends from the LASL Director, down through the A-Division Leader, to the A-5 Group Leader. The LASL Reactor Safety Committee (RSC) represents the Director in reactor safety administration. The A-5 Safety Committee reviews proposed documentation and advises the Group Leader about technical nuclear safety matters.

Earh operating crew that performs experiments is appointed by the Group Leader and consists of a crew chief and at least one crew member. The crew chief is responsible for all aspects of the operation and is instructed to consider personnel safety of paramount importance. A crew chief inust be a Staff Member. Both crew chief and crew member shall be in the control room during any approach to criticality or supercritical operation.

Training for crew chief or crew member consists of serving as an extra member of operating crews until judged by the Group Leader to be capable of formal participation, and attending a formal session on 
each machine to be operated and sessions on emergency procedures. All technical members of the Group participate in such training sessions, in cluding one session on emergency procedures, at least twice a year. Qualifications for either crew chief or crew member include examinations in accordance with ERDA Immediate Action Directive (IAD) 8401 . 6. "Retraining and Requalification of Reactor Operators and Supervisors," April 22, 1970.

\section{Action if Technical Specification is Violated}

A violation of any technical specification will be reported immediately to the A-Division Leader, the RSC Chairman, and, through the Chairman, to the LASL Director and a member of the ALO Operational Safety Division.

If the safety limit is violated, the assembly in question will be secured pending ERDA approval of further operation.

If any technical specification other than the safety limit is violated, the RSC Chairman will determine the appropriate action.

\section{Written Procedures and Approvals}

Pajarito critical operations are governed generally by the operating procedures of LA-4037-SOP, Rev.. 9 and by the emergency procedures of LA-4037-SOP, Rev., Suppl. 1. ${ }^{12}$ In addition, each critical (or nearcritical) experiment shall be covered by a written experimental plan approved by the A-5 Safety Committee, the A-5 Group Leader, and the A-Division Leader. Experimental plans shall include the following items as applicable: operational limits, purpose, materials; description, procedures, and safety evaluation. If the experimental plan introduces a unique, significant safety question, RSC approval is also required; any experiment with explosives shall be considered to be in this category. Any departure from the procedures of $\mathrm{LA}-4037-\mathrm{O} O \mathrm{P}$, Rev., shall be spelled out in the experimental plan.

A departure from an experimental plan or operating procedure that presents no unique, significant safety problem requires the Group Leader's approval. Other departures or modifications require approval by the RSC.

\section{Records}

A $\log$ of the operation of each assembly, with reference to safety features, shall be maintained. At the end of each day's record, the status of the assembly shall be noted. Safety features to be noted routinely are results of scram tests, instrument response, and scram monitor settings. There shall also be a log of maintenance and modification of assembly machines.

Other records shall include material covered in Group training sessions, attendance at those sessions, minutes of the A-5 Nuclear Safety Committee, and dates and results of examinations.

\section{Audits}

Independent review of documentation, facilities, and operations, in accordance with ERDA Appendix 8401 and IAD 8401-7, falls within the province of the RSC. Such review is supplemented by technical reviews requested of the A-5 Safety Committee or undertaken voluntarily. This committee meets at least four times a year.

\section{Procedural Matters}

Manual operations with fissionable material, such as storage and transfer, shall be conducted in accordance with ANSI Standard N16.1-1975. ${ }^{11}$

Before a critical experiment begins, all members of the operating crew shall review the experimental plan.

During nonoperating periods, the key that controls the operational power switch at the console shall be locked in a safe file or be in the custody of a person designated to control entry to the Kiva area when the radiation field is significant.

The crew chief's approval is required for any entry into the Kiva area during an operational period.

Any unexpected behavior of equipment during a critical experiment should be evaluated and resolved before further operation; if a participant is not satisfied with the safety of a proposed action, the experiment shall be suspended until the doubt is resolved.

Additions of reactivity (beyond those permitted by ANSI N16.1-1975 ${ }^{11}$ ) shall be guided by neutron 
detector response. During an initial approach to criticality, effects of reactivity additions shall be plotted and each step should be understood before a subsequent addition is made.

No reactivity additions shall be made simultaneously by two or more distinct methods or by two or more persons unless the effect of each addition has been measured.

\section{REFERENCES}

1. W. U. Geer, P. G. Koontz, J. D. Orndoff, and H. C. Paxton, "Safety Analysis for the Los Alamos Critical-Assembly Facility," Los Alamos Scientific Laboratory report L.A-4273 (1969).

2. W. U. Geer, P. G. Koontz, J. D. Omdoff, and H. C. Paxton, "Hazards Evaluation for the Los Alamos Critical Assembly Facility," Los Alamos Scientific I_aboratory report LAMS-2698 Rev. (1962).

3. Code of Federal Regulations, Title 10, Part 100, "Reactor Site Criteria," see Sec. 100.11.

4. T. F. Wimett, R. H. White, H. C. Paxton, and J. D. Orndoff, "Kinglet Safety Analysis," Los Alamos Scientific Laboratory report LA-4797-MS (1971).

5. G. R. Keepin, Physics of Nuclear Kinetics (Addison-Wesley, Reading, MA, 1965).
6. T. F. Wimett, R. H. White, W. R. Stratton, and D. P. Wood, "Godiva II-An Unmoderated PulseIrradiation Reactor," Nucl. Sci. Eng. 8, 691-708 (1960).

7. M. S. Dunenfoild and R. K. Stitt, "Summary Review of the Kinetics Experiments on Water Boilers," Atomics International repc:t NAA-SR7087 (1963).

8. American National Standard, "Safety in Conducting Subcritical Neutron-Multiplịcation Measurements In Situ," ANSI N16.3-1974.

9. J. D. Orndoff, and H. C. Paxton, "Operating Procedures for the Pajarito Site Critical Assembly Facility," Los Alamos Scientific Laboratory report LA-4037-SOP, Rev. (1973).

10. American National Standard, "A Code of Good Practices for the Performance of Critical Experiments," ANSI N405-1975.

11. American National Standard, "Nuclear Criticality Safety in Operations with Fissionable Materials Outside Reactors," ANSI N16.1-1975.

12. H. C. Paxton, "Pajarito Site Plan for Radiation Emergency," LA-4037-SOP, Rev., Suppl. 1 (1973). 